\title{
The Bush War to Save the Rhino: Improving Counter-poaching Through Intelligence
}

\section{Kristian Gustafson, Touko Sandstrom \& Luke Townsend}

To cite this article: Kristian Gustafson, Touko Sandstrom \& Luke Townsend (2018) The Bush War to Save the Rhino: Improving Counter-poaching Through Intelligence, Small Wars \& Insurgencies, 29:2, 269-290, DOI: 10.1080/09592318.2018.1435220

To link to this article: https://doi.org/10.1080/09592318.2018.1435220

曲 Published online: 20 Mar 2018.

6 Submit your article to this journal

Џll Article views: 205

View Crossmark data $[\pi$ 


\title{
The Bush War to Save the Rhino: Improving Counter- poaching Through Intelligence
}

\author{
Kristian Gustafson, Touko Sandstrom and Luke Townsend \\ Brunel University, Hamina, Finland
}

\begin{abstract}
The rhino is going extinct due to poaching at a rate which far outstrips current law enforcement or conservation efforts to halt their decline. A critical aspect of counter-poaching failures to date is an inaccurate view of the nature of poaching as a crime. Rather than demand-side efforts, attacking elusive smuggling networks or expensive technical solutions like drones, this article notes how a quasi-military tactical approach of 'combat tracking' offers the best way to protect the species. Based on wide ranging interviews and fieldwork across dozens of parks in southern Africa, it demonstrates how the current restricted range of the rhino, and the rarity of skilled poachers, makes a tactical solution the most effective to date.
\end{abstract}

ARTICLE HISTORY Received 21 August 2017; Accepted 24 October 2017

KEYWORDS Poaching; intelligence; bush war

The rhinoceros is going extinct. That, at least, is the sensible projection to make when one looks at the pace of their demise due not only to habitat loss and general human encroachment, but specifically poaching. The significant efforts made over the last few decades to prevent the extinction of such 'charismatic megafauna' have not achieved their hoped-for aims. Poaching of Africa's rhinos has escalated exponentially from an average loss of 0.17 rhinos per day (a total of 62 rhinos) in 2007, to 2.04 rhinos per day (a total of 745 rhinos) in 2012 and getting worse. ${ }^{1}$ During 2014, in South Africa alone, a staggering 1215 rhinos were killed by poachers: roughly one every eight hours. One thousand one hundred seventy-five rhinos were poached in South Africa during 2015. ${ }^{2}$ With officially only approximately 5000 Black Rhino still extant and a further 20,000 White Rhino at the time of writing, the foreseeable future of these species cannot even be numbered in decades. Privately, sources in African parks have told the authors that even these numbers are inflated, and in reality, far fewer of both species are believed to remain. ${ }^{3}$ One recent model puts total extirpation of African rhino species in less than 20 years' time. ${ }^{4}$ This is not inevitable. As the 
authors of that study note, 'for rhinos, extinction is an option in the control of humans. ${ }^{5}$

Yet, we have not yet forestalled that option. Conservationists and governments have failed to halt the catastrophic decline of the African rhino because they have been approaching the problem with the incorrect approach based on a misunderstanding of poaching as a crime. Historically, poaching has been treated as an organised criminal activity analogous to narcotic production or organ smuggling; protection of the animals themselves has been treated as an issue of zoology or animal husbandry. Neither set of approaches is correct. In fact, with the current stunning rate of decline, nothing will work to preserve the rhino from extinction other than to treat the poaching of rhino (and, also, elephant) as effectively a security issue. Poaching both the rhino and the elephant require specific, rare skills and is fixed to a tactical approach of tracking and stalking the animal. This is the single chokepoint which can be attacked and defeated with the current resources, and in time to save the rhino and halt the rapid decline of the elephant. This more securitised approach to counter-poaching is also likely the best method to combat large-scale bush-meat poaching or the collector poaching seen with the pangolin and other exotic species in Africa's parks and game reserves.

The authors of this article conducted hundreds of interviews across major national parks and game reserves in central and southern Africa since 2014. They engaged with rangers, zoologists, conservationists, trackers, poachers and guards. The contrast between the conservation approaches in the parks where the rhino is being protected (such as the Savé Valley Conservancy in Zimbabwe) and where it is not (such as in Kruger National Park) is marked. Working closely with the rangers in these parks, the authors gained fresh insight to the nature of the 'food chain' of poaching in Africa, going to the very tip of the supply-end, the tracker/poacher himself. It is this information, provided by the men \& women who struggle daily and at the threat of their own lives to protect the rhino and elephant, which allows the authors to suggest a new paradigm for counter-poaching. Some interviews have been anonymised at the request of the interview subjects.

This article aims to contribute to the survival of the Rhino by reformatting our approach to the conservation of the rhino and, to a lesser extent the elephant and other species in protected areas and parks. Saving these species is a matter, effectively, of securing an asset which conservationists and governments already own: the threatened animals, which exist almost without exception within parks and protected areas, already having been extirpated from 'the wild.' 6 Unlike the 'war on drugs', it is possible to wage a war on poaching: the poacher is a known, armed individual who is not easily replaced. The main good being 'produced' is entirely in our hands, and ours to protect within a delimited space. If we treat this problem not as organised crime - which at the supply side, it resembles only superficially - but rather as a quasi-military, essentially tactical problem 
of defending the rhino or elephant physically, we have an opportunity to buy time for more comprehensive long-term demand-side solutions to take effect. Target the professional poacher - the true choke point of illegal wildlife trade, to provide security for the animal.

\section{Poaching as Organised Crime}

If we are to blunt or defeat large-scale organised poaching, ${ }^{7}$ it is necessary to have a clear view of the activity as a criminal act. Currently there is only a very thin and largely anecdotal literature on the nature of wildlife trafficking. ${ }^{8}$ In this study, we identify the sui generis qualities of the crime, and in doing so, we can also understand how approaches which have been successful against other organised criminal activities have failed to prevent the decline of the rhino and the elephant. In scientific literature and popular news, there is a tendency to label poaching as organised crime. ${ }^{9}$ It is quite common to group poaching together with supply, sale and transport of illicit goods, especially narcotics. While partially true, this labelling is quite detrimental to counter-poaching efforts, and indeed some research has suggested it is actively harmful. ${ }^{10}$

The effect is easiest to understand when we divide an organised criminal activity to three phases - supply, trafficking and demand/distribution. The trafficking networks are the same as those of, for example, narcotics. The demand/ distribution side also has many common qualities between poaching and illicit goods trade. However, the true heart of the activity is the supply - the act of poaching itself - which does not share much with other types of organised criminal activities. In fact, there is a distinct lack of any evidence pointing to poachers fulfilling any definition of organised crime. Comparing most definitions, as compiled by Frank Hagan, with actual research shows just this. ${ }^{11}$ There is a notable lack of restricted membership, professionalism, rigid organisational structures and for some syndicates even violence with the supply side of poaching. Common opinion that poachers are master criminals ${ }^{12}$, while useful for fund raising, is quite detrimental to the actual cause.

In using the organised crime label, counter-poaching efforts are made more difficult for three reasons. In the first instance, the 'organised crime' label focuses efforts at the transnational level, or on the 'kingpins', who are without exception hardened criminals that have been trafficking for years. ${ }^{13}$ These efforts have given and continue to give poor return for the resources used..$^{14}$ In part, combating the demand and trafficking networks in areas where rule of law is diminished and corruption rife - specifically the main market of Vietnam and African post-revolutionary states - does not work with other illicit goods either (The Guardian, 7 May 2016). ${ }^{15}$ Last, the label forces an association of supply side tactics of organised crime with poaching. The illicit goods trade is fought at the supply level with law enforcement methods that are largely incompatible or inefficient with poaching. It is this last point which warrants a longer discussion. 


\section{The Supply Side of Poaching}

Poaching of elephant or rhinoceros almost always begins with a middle man ordering a hunt in one form or another. The majority of researched parks also see weapons and spending money delivered by this middle man who is the first link in the trafficking network. ${ }^{16}$ Non-syndicated, or opportunistic, poachers generally lack this supporting and enabling structure, but they also do not pose a serious threat as they often lack training, are easy to catch and have trouble selling their product. ${ }^{17}$ There are a few differences in how syndicates gather poaching parties. Some examples include the middle man contacting a trusted man in the crew to put it together, while others see the crew already existing as an established unit that mostly works together. ${ }^{18}$ Middle men come from a wide range of backgrounds from retired poachers to corrupt law enforcement officials and as such are easily replaced when disrupted. Networks that have long been in operation generally also seem to be more vertically streamlined and have a stricter hierarchy, although they are very different in hierarchy when compared to actual organised criminal networks, organised as a small syndicate or cell of three or four, rather than a vertical hierarchy. ${ }^{19}$

Rhinoceros poachers hunt almost always in a group of three or four, regardless of the geographic area. These parties include a shooter, a horn cutter and a carrier. Generally, the shooter is the most senior of them and receives the most pay, but there are counter-examples to this. There is a variety of backgrounds between rhinoceros poachers, but there are often ex-military and other specialist skill sets involved. ${ }^{20}$ Poaching is fairly difficult in places with less dense rhinoceros populations and made even more so by the presence of rangers. Rhinoceros can move up to $20 \mathrm{~km}$ per day and tracking them in savannah type terrain requires a seasoned tracker. Combined with search and destroy activity of rangers especially after the poachers have fired a shot, the poachers must have knowledge of the terrain, be well conditioned, be able to avoid rangers and aggressive animals present in protected areas. ${ }^{21}$

Elephant poachers function in a similar manner, but the conditions of elephant poaching create a few specific requirements. The main difference between elephant poachers is that they can feature multiple shooters, from one to three, and have larger number of carriers, even up to 20 . This is due to the fact that ivory has less value by kilogram and tusks are fairly heavy. ${ }^{22}$ Shooters can be highly professional and specialised, so much so that in Northern Tanzania only a few shooters have been identified doing almost all of the poaching, identifiable by their home crafted ammunition. Elephants are easier to track and find as they move in bigger herds. However, the biggest tusks are usually found on bull elephants who are solitary creatures and thus also need expert tracking. ${ }^{23}$

Elephants and rhinoceros live in protected areas, and in these protected areas rangers have the jurisdiction to enforce the law. While the legal details differ from country to country, the essential point to understand is that the animals 
are already in an area that is monitored, has a security framework, has limited boundaries that need to be breached in order to poach and, while the animals are confined to areas, they are not static. The setting is very much like a counter-insurgency. There is a protected area with a protected community against which a group of specialised military-like units act- the only real difference between poaching and insurgency is the motivation of the poachers vs. insurgents. Indeed, in some regions such as Garamba National Park in the northern DRC, and even in much more peaceful Gabon, the poachers are insurgents. In the former case, these are either local DRC rebels, militias from South Sudan or Sudan, and even elements of the Lord's Resistance Army. ${ }^{24}$ In Mwagne National Park in Gabon, for instance, the increasingly large armed groups are factions coming out of neighbouring Republic of Congo, and in Gabon's Minkébé, it is from Cameroon, perhaps with parties backed by that country's government. ${ }^{25}$

\section{Comparing the Supply Side}

It is worth comparing poaching to other major illicit trades to see how, on the supply-side, they are fundamentally different: approaches taken from counter-narcotics or counter-arms-smuggling and applied to poaching are unlikely to work as they share little in common. A clear view of the nature of the 'product' in poaching - the animal - and its location (now principally in the hands of authorities) underline the different approach required to stop the trade at the demand end.

The main three illicit goods associated with organised crime internationally are narcotics cultivation, the organ trade and illegal arms trade. These three are each different from the other and are quite well researched. On the surface, they have distinct features that are comparable to the specifics of poaching. Narcotics cultivation is location specific and heavily dependent on the area, as the main commercial narcotics associated with organised crime can only be grown in specific climates without the use of greenhouses (leaving aside marijuana, now increasingly legal in many jurisdictions). Narcotics also share a similar demand structure to rhinoceros' horn and ivory. They are mainly used for recreational purposes, unlike illegal arms and organs. Organ trafficking does not share the location specificity of poaching and narcotics, but like poaching, it involves the use of highly skilled professionals and considerably small trafficked items. Arms trafficking has a similar profile to poaching in terms of security. When produced, arms are usually legal, but they are diversified from this legal status by different means. In a sense, this compares quite well to rhinoceros and elephant, who by themselves are not illegal, but the product extracted from them is - and this extraction can only be done by breaching security measures.

The main cultivated narcotics associated with organised crime are coca, opium and cannabis. Two of them, opium and coca, are heavily restricted geographically and also by climate. Cannabis, in smaller scale but yet large enough, 
can be grown everywhere in the world and thus makes for a poor comparison to poaching. The legalisation or decriminalisation of marijuana or its derivatives in many countries around the world, in part because of its legitimate medicinal uses and changing societal views on its use, further cause us to exclude it from comparison here.

Coca is cultivated almost exclusively in a relatively small area in South America: Peru, Bolivia and Columbia are the only nations where significant amounts are grown. The fight against coca cultivation shares some similarities to the rhinoceros' problem, specifically that it is actually legal to grow coca in Bolivia (The Guardian, 24 April 2015). This is an interesting contrast to the legal hunting issue that the rhinoceros wars face. Supply-side strategies and tactics against coca cultivation include mass crop eradication and processing facility seizures and destruction. Mass eradication is very ineffective, and while targeting of processing facilities has shown a bit more promise, the whole supply side combat has been extremely costly. According to a 1994 RAND study an 800 million US dollar injection into supply side strategies netted a mere $1 \%$ loss in the end product - approximately three times more expensive than targeting domestic markets or the trafficking system. ${ }^{26}$

Opium shares a similar story. In Afghanistan and Myanmar, where the bulk of the world's opium is produced, authorities have also had very little success with large-scale eradications, or with voluntary crop replacement. These strategies have also created a mass of social problems, especially in Afghanistan where the local population is very poor and unable to cope through forced eradication and loss of crops. ${ }^{27}$ Some success has been drawn from targeting production facilities that process the poppies. These facilities use large amounts of chemicals for the production and this has been used as a targeting tool. Alas, for rhinoceros horn nothing like this exists.

Thus, the campaigns against illegal narcotics make for a difficult comparison. There are very few lessons that are directly transferable to counter-poaching. The main problem is that the supply encompasses wide areas in terms of area for cultivation, and for processing crude structures are used that can be set up everywhere. In terms of geographic spread, production processes and the scale and bulk of resulting product movement, there are few similarities which would commend borrowing tactics from counter-narcotics to counter-poaching.

Organ trafficking seeks its victims among the extremely poor mainly from the global south. The term organ trafficking is a misnomer, as most illegal transplantations happen in a location where the unwilling donor and/or the receiver have travelled to or have been trafficked to. The Hollywood and tabloid purported myth of forcibly removing organs in a back alley and taking them to another country is quite far from the truth, because the ischaemic times for organs are fairly short. The extracted organs need to find their receiver in as short a time as a couple of hours. Some organ trafficking cases are thus also human trafficking cases. $^{28}$ 
These networks share a similarity with rhino poaching, as they necessarily feature a highly skilled specialist who does the procedure. Targeting these professionals is often problematic, as there are often cases where they might not even know they are doing a crime. Forged documents and tricked patients are more than often used in organ trafficking cases. ${ }^{29}$ This makes targeting the networks and the professionals problematic - unlike a rhino poacher who is very identifiable when they enter a national park.

On the supply side, organ trafficking networks can start nearly anywhere and seeking donor-victims and setting up the network can be done by nearly anyone without any specialist skills. The victims are also not in a short supply, although willing victims might be. There is no set area where the networks can function and it demands quite a lot of effort to pinpoint these people, even though they usually function in a semi-public role to lure in possible victims. The tactics used against these networks are usually slow operations making use of various intelligence methods and more akin to classical police work. These networks are very rarely disturbed and the efforts are usually targeted against the professionals who do the actual procedure or the recipient patients travelling for the unethical procedure. ${ }^{30}$ Interestingly, the crime is also 'stateless', in that there is no international legal code which controls or forbids the movement of organs internationally. ${ }^{31}$

Organ trafficking and rhinoceros poaching, however, share an interesting similarity. They both make use of highly skilled professionals, whose identification and removal will usually destroy the network. The tactical solution to identifying, locating and capturing these professionals is vastly different though.

Illegal arms trade is a diverse field of organised crime. The supply comes from arms that are diverted from civilian or national stockpiles and a single case can range from a squadron of attack helicopters to a simple, single, $9 \mathrm{~mm}$ parabellum cartridge. These stockpiles are in a constant flow, are often easily tracked by serial number and so the whole chain from the manufacturers to the users is vulnerable to attack.

There are a few main methods of diverting weapons and ammunition from their stockpiles. Looting, theft and corruption are the most common, but legal purchase and then diverting to an illegal use has also been witnessed in large scale. The supply side strategies include three different categories: physical security, accounting and monitoring. Physical security includes fences, cameras, armed guards, locks and deployed security forces. Accounting involves stockpile management through stock records, what has been issued and what has been expended. Monitoring includes measures through which firearms and ammunition can be tracked to specific lots or manufacturers, and reports and auditing of existing stockpiles. ${ }^{32}$

Interestingly, tactics from these three groups have all been used in counter-poaching. Especially monitoring methods, such as rhinoceros horn colouring or poisoning have been ineffective. Accounting has been poor in many countries 
and at least in Zimbabwe has raised awareness to how bad the situation with black rhinoceros truly is. Physical security is of course being utilised all over Africa and at first glance seems to be quite well applicable - perimeter control through fences, restricting access and patrolling the area all seem like good features. ${ }^{33}$ And in fact they are, except there are a few very important key differences. Rhinoceros move around vast distances and most, if not all, of the parks with rhinoceros can control access only in a limited way, due to tourism, long borders and a lack of funding for physical security.

Fighting poaching requires a very different mind-set from organised crime in the supply side. In a poaching situation, an armed assailant enters a protected area. There is little to counter this in practical law enforcement methodology against organised crime. As was pointed out above, the problem here is that these other forms of illegal trafficking have been viewed as analogous to poaching, and with the comparison the policing tactics and international policies used in those other situations have crept into counter-poaching. For example, the counter-narcotic mind-set where the product itself is 'attacked' has been utilised in many parts of Africa - these are the so-called animal-centric methods, horn removal and horn poisoning of rhinoceros. These methods have not been shown to deter poaching significantly, and at the same time they are very expensive. ${ }^{34}$ It has 'no effect on poaching rates because poachers ignore, or are not aware of, the difference between treated and untreated rhino horn, and additionally because poachers are not the end-users.' ${ }^{35}$

Thus, discussing counter-poaching tactics at a broader scale, there are some aspects of organised crime law enforcement that can be utilised. However, this utilisation needs a very thorough understanding of the poaching event and the surrounding conditions. Making a direct comparison between organised international crime and poaching and, what is more, treating poaching as organised crime, will not develop this understanding because it disregards all the factual data. First, because there is no evidence that poaching syndicates function like organised criminal networks, and second, because the act of poaching is not meaningfully comparable to the supply side of organised illicit trade of goods.

We can see how attempts to map understanding of global smuggling of contraband has inaccurately coloured the understanding we have of the poaching problem by looking at one key diagram that is frequently used by counter-poaching organisations: the 'poaching pyramid', the version provided here ${ }^{36}$ used by the UN CITES group, but also used by Interpol and other organisations (Figure 1).

This diagram might perhaps work if representing production of coca or heroin, but it does not look like rhino poaching. In the first instance, we can note that the top of the 'chain' (level 5) of international poaching is not a small number of consumers but actually quite a large number. ${ }^{37}$ But that matter is not what particularly concerns this piece. Rather, we can point to two chokepoints: at level 1 (the poacher) and at level 4 (the international trafficker). It is indeed the case that there 


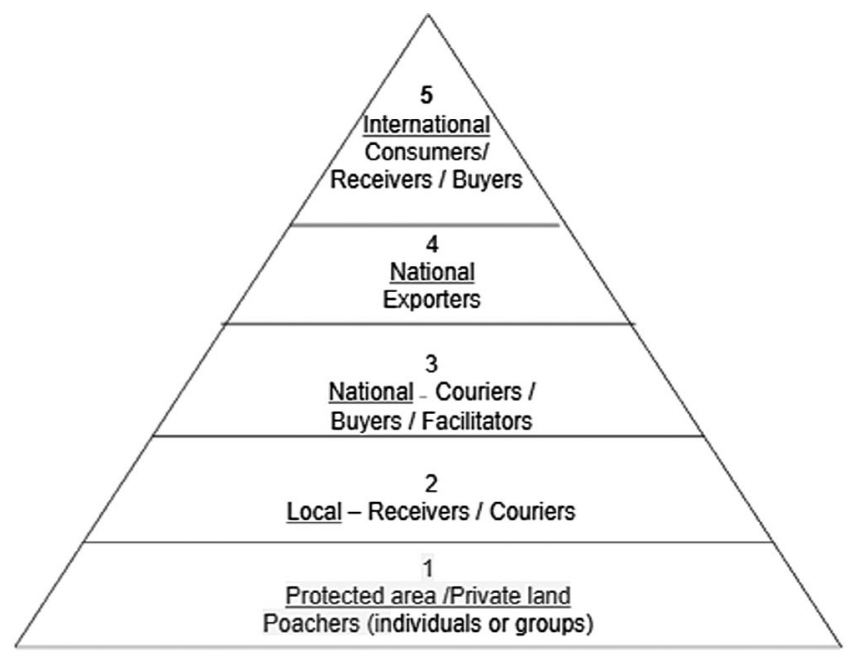

\section{Five levels in the structure of organized crime groups involved in rhinoceros poaching and illegal rhinoceros horn trade in South Africa}

Figure 1. The CITES ‘Poaching Pyramid'.

is no lack of those willing to take part in the poaching endeavour - poverty and hunger will always trump abstract ideas like environmental integrity if you are an African villager - but the act of poaching cannot happen with porters alone. The act of stalking and shooting a rhino, as mentioned above, requires a narrow skill set, for if a poacher wishes to shoot a rare and elusive rhino he must find it. Therefore, the poacher must track the rhino, making him vulnerable to counter-poachers. The skill to track rhino for poaching is not widely available. Contrary to commonly held beliefs, there are a finite number of people who have the right personal characteristics and skills necessary to hunt rhinoceros and to a lesser extent elephant. ${ }^{38}$ If these people are disrupted they are not easily replaced and the skills not passed on. ${ }^{39}$ At Ngorongoro Crater, in northern Tanzania, poachers are known as 'fundi' meaning 'specialist' in Swahili, so rare have their skills become. ${ }^{40}$

At level 2 and 3, there is no lack of people capable of trafficking within any given country in Africa, so these levels are correct. ${ }^{41}$ But another major chokepoint exists when moving across international borders: these smuggling routes are controlled by a limited number of established actors, who are generally product agnostic: they will smuggle any low-bulk/high value item they can profit from. As Peter Younger, director of Interpol's wildlife crime division noted, 'once you have that [smuggling] pipeline open, then you can smuggle pretty much anything down it. So if you can't source wildlife today, and somebody says 'Listen, I've got a shipment of heroin, or I've got some illegal immigrants, or I've got some prostitutes that I want to get to somewhere', you have a ready-made pipeline. ${ }^{42}$ Ivory is slightly different than rhino horn: the poaching is easier, the 
trafficking is harder and requires specific infrastructure and to store and transfer the larger bulk. Still, however, the structure from supply-end to demand-end would in no way look like a pyramid. What we have instead is not a regular shape, but one of several choke points, looking perhaps like a spinning top as at Figure 2.

Using this diagram as our conceptual starting point, we can see that there are two chokepoints that we might best choose to attack: the poacher himself and the international trafficker. Since efforts at stopping international smuggling of anything has rarely proved effective due to the innate resilience of smuggling networks. ${ }^{43}$ We might therefore turn our attention to the poacher and the poaching party.

A better way to conceive of the poaching party is to drop any reference to international illicit trades and look to a harder-edged example: insurgency. Insurgency is a heavily studied phenomenon, and here we look more at its tactical aspects than its political ones. ${ }^{44}$ We can identify clearly that large-scale poaching networks do exploit the political weakness of many African states to better profit from the crime, but the ambitions of the poacher are not in the first instance political. Rather, we refer to the way that poachers operate within and through communities, and the way that they employ violence. The poacher is by legal definition illegitimate, and operates to avoid a response from the legitimate authorities. Equipped with ample cash, poaching syndicates are able to hire porters and buy supplies from local communities - an incentive that works against the authorities and undermines conservation efforts by denying those protecting the animals any local knowledge about the presence of poachers. But

\section{The Rhino Poaching Chain: Supply to Demand}

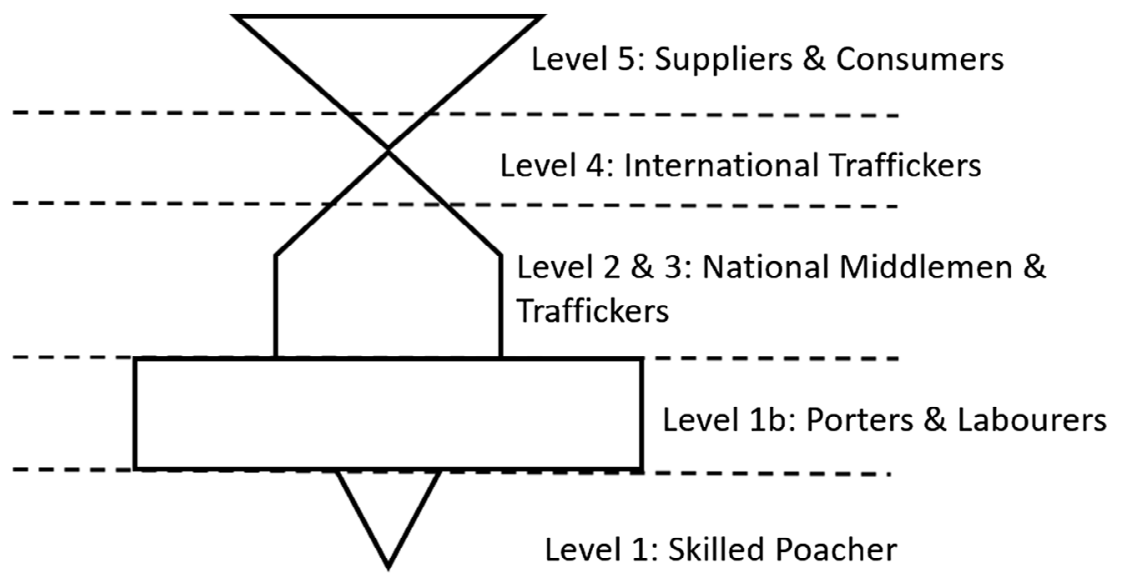

Figure 2. Alternative poaching model. 
the act of poaching must extend beyond informal networks of local assistants, as the act in the end cannot happen without armed men finding and killing a moving target, the animal.

The poaching party thus resembles any of the insurgent groups operating in the Southern African 'bush wars' of the 1960s-1980s: armed groups in section to platoon size (that is, from 5 or 6 up to 30 or 40), moving quietly to find their target, kill it and remove themselves to safety. Armed well but without support weapons (anything more cannot be carried by a man moving quickly), they do not seek out confrontation with stronger government forces except when luck or timing presents them with local superiority of force. They do not seek to hold ground, but to exploit the inability of the governing authority to protect its terrain and key assets from the insurgent - a small group operating quietly over a very large terrain. But speaking tactically, the governments of South Africa and Rhodesia were, in their bush wars, able to neutralise the insurgents effectively. ${ }^{45}$ While their defeat politically was just and inevitable, operationally both governments developed tactics capable of blunting and even defeating the operational forces of the insurgents sent against them.

We may add, of course, that in parks such as Garamba in the DRC, the poacher does not just resemble an insurgent: this is in fact his role. Poaching is a business or logistic solution to their tactical or operational problems. ${ }^{46}$ The LRA may be generating a significant portion of their operational budget from poaching, as may some militias in South Sudan (The Telegraph, 12 Jan 2016). They are armed and equipped for 'low intensity' warfare.

Operations against the demand side of poaching are not likely to pay off in the time needed to preserve the rhino and elephant in the wild. Supply side enforcement approaches based on misunderstanding of the phenomenon are not currently working. Thus, it is to a 'bush war' approach we can look to find a meaningful, timely response to the devastating poaching plague currently sweeping through sub-Saharan Africa.

\section{Poaching as a Tactical Problem}

The main skill involved in stopping poachers - that is, the sine quo non shooter on the supply-side rather than the onwards smugglers - is combat tracking. This term likely arises from the same skill used by South African and Rhodesian forces in the Bush Wars, brought into use in conservation by veterans of those wars now protecting animals. ${ }^{47}$ Start with the idea of poaching as a tactical problem, with tactics being 'the art of disposing forces, deploying them for combat to achieve a decision which furthers the operational aim with the maximum economy of effort. ${ }^{48}$ More plainly, it is a problem involving the disposition and use of people and weapons in an engagement, in order to achieve an effect as efficiently as possible. The poacher must find his prey, approach it without disturbing it or being disturbed, kill the animal, remove its tusks or horns and then extract his 
team and its booty to a safe place. The single point of failure for the poacher is then the animal: if they can be prevented from tracking and shooting the animal in the first place, there is no onwards criminal trafficking chain. So, if the parks wish to protect the rhino, elephant (amongst other HVS like big cats) from the poacher with the maximum economy of effort, they must also track the animal, where they are likely to encounter anyone else - the poacher/tracker - wishing to find the animal. Combat tracking has so far had the most significant effect in stopping the loss of animals because it attacks the most vulnerable chokepoint in the rhino poaching chain.

The variety of origin and distances travelled by poachers to their chosen hunting grounds highlights the rarity of their skill. ${ }^{49}$ Because the situation has gotten out of hand there, many more local people are learning the skills required by joining a poaching party that contains an experienced tracker, learning from them and then after a period of successful poaching, starting their own poaching group. Due to the lack of success so far in intercepting poachers in Kruger, there is very little deterrent to a potential poacher, it being estimated that there are up to 12 poaching parties in Kruger at any one time..$^{50}$

Elsewhere however poachers are found to cross borders and travel some distance in order to ply their trade. Zambians are used by poaching syndicates in Zimbabwe, and Zimbabweans poach in South Africa. ${ }^{51}$ In Gabon parks along the coasts (Akanda, Loango, Mayumba, Pongara and also Wonga Wongué), poachers come from China, Congo and Cameron, often from the sea, in the form of groups who conduct illegal fishing and night-time hunting..$^{52}$ Even in Kruger with its mass of local poaching groups, Zimbabweans have been caught. Poachers travel to where they perceive there is a soft target and avoid what are considered hardened targets much closer to home. As the protected area became more proficient at protecting themselves, so too the poacher is forced to become more of a specialist. Weapons and ammunition have to be modified to lessen sound and increase penetration power and only after careful coordination and planning can the fundi poach a specifically targeted, lone elephant. ${ }^{53}$ Taken together, this has meant that the poachers are easier to identify because of the signature way they prepare their ammunition, there are less of them capable of the complexity required and less animals are poached in total, because of fear of interception by rangers the longer the poacher takes.

Aside from the difficulties in acquiring the skill to track animals in the bush in the first place, a poacher must also overcome a number of other barriers the poacher will also have to accept that he is being hunted by armed rangers as well as the other threats posed by the African bush. A poacher is motivated by monetary gain, not by ideological or political reasons. This makes them a lot more risk averse than a terrorist or insurgent and it is counter to their motivation to die in the process of acquiring wealth. Tracking is also a mentally draining, physically demanding and in the heat of the day, arduous task, involving walking for up to twelve or fourteen hours a day and constant observation and thought. 
An incursion into a protected area may involve three or four days of constant tracking. Many poachers are found to be carrying high-strength painkillers to overcome the discomfort this effort causes their bodies. ${ }^{54}$ So a successful poacher needs to be well motivated. For all these reasons, the ability to track rhino effectively is not widely available.

Poachers are not hardened criminals and can be countered if funding and expertise are available. Poachers in many places have not been effectively challenged or disrupted by law enforcement. As a result habits common to criminals and insurgents, such as good information security, are often non-existent. Social media is used to brag about when poaching is going to take place and when it has been successful. ${ }^{55}$ Phone numbers and SIM cards are sometimes kept for a period of years without change. ${ }^{56}$ Even movements and habits are not varied as there is a feeling that there is no threat. Poachers have even been interviewed by newspapers in their own homes, without fear of consequence. Most of the criminals who make up the poaching networks are known to those conducting intelligence at the park level. The disruption of key personalities in these networks would grant significant periods of reduced poacher activity.

Poachers, where they have been countered effectively in the past, are often very averse to trying again in the same place for extended periods. After a series of poacher detentions at Stanley and Livingston private game reserve a period of three years without a poaching event was enjoyed..$^{57}$ After combat tracking was introduced to Savé Valley and a series of contacts ensued, a twelve-month period free of poachers was enjoyed, where previously two poaching events a week were occurring. Similar results to these are demonstrated in many other locations, such as Ngorongoro Crater, Lower Zambezi National Park and the Selous Game Reserve (though the decline in poaching was shorter lived here). ${ }^{58}$ Kruger seems to have suffered from the dual appeal of being ineffective at countering poaching (although this is changing) and having a massive rhino population, making the risk worthwhile to the poacher given the greater chance of reward. ${ }^{59}$

Resource levels to protect the animal matter, but not as much as mind-set and counter-poaching expertise. Many of those entrusted with countering poaching within a given protected area are conservationists or ecologists - not people of law enforcement or security background - who have held their positions as managers for decades. Their primary tasks as they see them are the management of the environment in their care and the handling of problem animals and associated management or husbandry tasks. ${ }^{60}$ Tactical counter-poaching is something they do in addition, outside of their education and training. During normal times this was totally appropriate. However, with the unprecedented pressures of the last four years the situation has changed and the mind-set of those in these positions has struggled to change with it. Tactical solutions either hold little interest for the manager in this position or are simply met with a lack of comprehension or ability to apply. 
There is a focus on expensive animal-centric solutions like de-horning and horn poisoning and untried or 'nice to have' technological solutions, like Unmanned Aerial Vehicles (UAVs). ${ }^{61}$ These tie up large amounts of funds which could be better directed at proven, practical approaches, such as combat tracking and human intelligence-based solutions. To provide some context, each de-horning costs approximately US\$1,000, which represents four months' wages for a qualified elite tracker. To operate an effective drone programme in one small park in Kwa-Zulu Natal Province costs $\$ 500,000$ a year. ${ }^{62}$ The province has 23 other parks and reserves. That scales up to $\$ 12$ million for the province. Even if this was implemented, when a drone does find a poacher (which the drone does not do itself: each drone requires pilots as well as trained image analysts beyond the immense logistical and maintenance requirement), it still requires a highly trained and well-led ranger on the ground to make the interception. Applying counter-poaching measures and paramilitary solutions is less clinical sounding than using UAVs, and is often reacted to with suspicion or a lack of comprehension, though it represents a more sustainable and effective solution. Real gains, for relatively small amounts can be enjoyed by the counter-poaching approach. Savé Valley Conservancy in Zimbabwe with the addition of just seven elite combat trackers delivered a massive poaching reduction in $2013 .{ }^{63}$ Tracking as a counter-poaching method is poorly understood in many parts of Africa. There is a tendency to assume that it is reactive and that a tracker can never hope to catch up to a poacher by tracking, as the tracker is slowed by the process. This represents a lack of understanding of how to use the intelligence gained by the tracker.

Combat Tracking is an intelligence collection and prediction method, not just the following of footprints. Animals who are under greater threat are followed some hours behind, or areas are patrolled where previous poaching has occurred. When a poacher's tracks are identified the tracker does not attempt to catch up, but radios up the location, age and the direction of travel of these tracks. ${ }^{64}$ The head ranger then consults a map and makes an assessment of where the poacher is likely to be at present and where he will be in the near future (assisted by earlier, professional 'Intelligence Preparation of the Environment' - a systematic plotting of the opponents' tactics against the ground they are on). ${ }^{65}$ This is often made easier by the rhino themselves who are creatures of habit, with rangers often having a good idea of where the rhino is. The head ranger then sends out cut off groups to get between the poacher and the rhino, either with aircraft if available, or by vehicle, to cover the distance quickly. These cutoff groups then dismount and move in at different points along the poachers predicted path searching for the poachers' tracks. ${ }^{66}$ If the ranger finds he is ahead of the poacher, an ambush is set and an interdiction made.

This process is inexpensive and requires only one member per patrol to be combat tracker trained, the rest of the patrol being for numerical advantage. This goes some way to explaining why some large protected areas with 
comparatively small budgets are having more success than areas with much larger budgets and resources. One can see also how this is more than reactive anti-poaching, more than reciprocal action in response to a poaching event. It is counter-poaching, attempting to prevent the poaching event by targeting the poacher.

Conservation organisations such as African Parks have made strides in counter-poaching in part because of their focus on intelligence sharing between parks. Poaching is of course a dynamic business: it changes its profile depending on demand and adopts new techniques to counter established defences. But if parks share information they can help offset the poachers' dynamic advantage. Should one park notice a new poaching technique - say, use of poisoned watermelons to kill elephant - other parks can begin to identify individuals who have bought large quantities of watermelon from local markets. Should the size of poaching parties or their composition change in one region or park, rangers in other parks can adapt pre-emptively, changing their patrolling profile to look for the new technique.

Fusion of the intelligence between protected areas, not governments, is key. Trying to fix the poaching problem from the national level down is difficult. Most protected areas operate as states within states or'mini-states.67 This makes them independent, but isolated. They cannot report to or request information from state agencies that would traditionally be turned to, because of high levels of corruption. Further, these protected areas within a given country rarely communicate with each other as they are often competing for the same resources. Massive amounts of data including names, phone numbers and routines of key individuals are trapped at the park level, because parks do not trust government agencies, often with good reason. Those that are too effective will affect the revenue flow, or even uncover evidence implicating, corrupt individuals within government. If this is being reported through official channels, those being a nuisance to poaching will be removed from their positions. However, there are human intelligence networks focused against poaching that stretch from South Africa to the Congo, and these could be co-ordinated. Under the right circumstances, Parks are willing to share information. Game Reserves United (GRU) existed purely as an intelligence and security organisation funded by its members for the protection of their reserves. These reserves shared information internally and did their best to disrupt poachers, before they ever got to the reserve. This resulted in a 50\% reduction two years in a row within those areas that were protected by GRU. ${ }^{68}$ This was even more exceptional, given their location on the western boundary of Kruger.

The parks that have the best counter-poaching intelligence are those that have established local information networks in the communities in and surrounding the parks. This is a critical step for all parks across Africa who hope to preserve species of any type. This is not coercive intelligence gathering or corrosive informant networks: it is a matter of convincing the local populations 
that it is in their interests to maintain the integrity of the park because doing so will make life better for them. 'If a species pays, it stays,', ${ }^{\prime 9}$ as one analyst has said, speaking with a pure micro-economic outlook. Park-level intelligence against poaching (as in counter-insurgency) will work best when combined with community development and health-care, a general enfranchisement in the life of the park. When, as in Ngorongoro in Tanzania and in the Lewa and Borana conservancies in Kenya, the local population believe they will prosper more if the poachers are kept out, then it will be harder for poachers to operate: they will lack porters, local guides and will lose the intelligence war. ${ }^{70}$ So, conservation money needs to go to people as well as to animals.

\section{Conclusions: An Aggressive Defence of the Animal}

Halting the decline of the rhino at the hands of poachers has failed in part because of misconceptions on the nature of poaching networks. A clearer understanding of these networks which focuses on the keystone tracker/shooter is, on evidence to date, a more viable approach. While efforts to halt international trafficking, and to reduce demand should and must continue, the only way to save the rhino is to physically defend them in the limited time we have at current poaching rates. This requires intelligence, intelligence sharing and well-trained rangers adopting an aggressive counter-poacher approach based on combat tracking. Counter-poaching must take a tactical approach - to treat poaching as a tactical event in a larger bush-war - if it hopes to ever effectively protect the high-value species. This does not mean law-enforcement is set aside, but rather that it depends first on successful tactical behaviours. Law enforcement and conservation on their own will not save the rhino.

The counter-poaching approach encapsulated in Combat Tracking works because it targets the single point at which the poacher must approach the HVS, and is not sensitive to the price of ivory/horn, the involvement of sophisticated international syndicates and most other exogenous characteristics of CITESlisted trade. It does depend on several other factors which further commend the approach: We can note that it is not subject to the vagaries of law enforcement efforts across multiple jurisdictions, as it takes place entirely within the protected area or park, which in most of Africa permits the application of deadly force against armed incursion. Critically, it is dependent on good intelligence amongst the residents of the park and its environs. Park managers thus have a critical incentive to involve local populations in the protection of their park ecosystems to gain information. It is those parks who manage an integrated law-enforcement/community engagement approach who have had the best results (Majete National Park in Malawi being an excellent example) in pre-empting poaching and dissuading and arresting, rather than shooting, key poachers and trackers. ${ }^{71}$

There is an argument in the literature which criticises the securitised "counter-poaching" approach, which this paper may be seen to advocate. ${ }^{72}$ Some of 
these criticisms are valid in that they are aimed at counter-poaching techniques which have been misconceived, based as they are on an incorrect understanding of the structure of poaching networks. This paper has hopefully moved beyond these critiques by a better conception of the problem. It is imperative that the parks themselves play a role in halting the poaching war they are currently losing: the sole node they can affect is the skilled poacher, so they must, while other agencies continue their work (perhaps less successfully) at other levels of the poaching chain.

Throughout this paper, the authors have been conscious of a deep ethical question which we cannot, within the confines of our research or expertise, fully discuss, and that is the correctness of applying deadly force against people to protect animals. Across Africa laws have already been enacted by the various sovereignties allowing this expressly - the logic perhaps being that the greater good and welfare of any nation's citizens is increased not only by biodiversity, but also by the revenues generated by legitimate eco-tourism. We can also note, however, that those engaged in poaching in Africa today are substantially outlaws already, being engaged in or strongly linked to insurgency and rebellion. We may wish for a world where park rangers can deal principally with husbandry and conservation, but that is not the world that militarised poachers have allowed us to keep.

This article has focused strongly on rhino poaching, as this is the most critically endangered and most heavily poached HVS in sub-Saharan Africa. But the counter-poaching approach with its emphasis on intelligence as well as community engagement, can also help reduce other key threats to the viability of African parks, their environmental integrity and their species. There are other types of serious threat to the integrity of Africa's parks, and the solution offered here will not fit all of them. However, it can be said that a clearer analysis of the drivers of, for example, illegal charcoal production, exotic species capture and trafficking and bush-meat hunting/poaching, may find the approach detailed here may help also in reducing these destructive practices. Certainly, an intelligence $\&$ analysis-driven approach to conservation can only help to increase our understanding of the phenomena.

It is a sad reality now that Africa's once abundant biodiversity is restricted in many aspects only to protected areas. Whereas even a few decades ago the concepts described here could not have worked due to the huge range of space over which HVSs like rhino and elephant roamed, they are now restricted to relative pinpoints which can, and must, be defended. Africa's parks must now actively defend the species and spaces that foreign demand has driven to the brink.

\section{Notes}

1. Knight, "African Rhino Specialist Group," 7-19. 
2. Save the Rhino, "Poaching Statistics." Cf. Emslie, et al., "African and Asian Rhinoceroses," 1 . This describes a plateau in total numbers in 2012 after several years of significant growth.

3. Interview, LT and TS with M1, Law Enforcement Officer for Game Reserves United (GRU), May 2014.

4. Haas and Ferreira, "Conservation Risks," 9.

5. Ibid., 1.

6. Ibid., 6 .

7. See Davis and Brown, Bushmeat and Livelihoods. Subsistence bush-meat poaching and other types of ecological degradation are also significant threats to the environment, but are different in nature, so will not be dealt with in this article.

8. Wittig, "Poaching, Wildlife Trafficking," 77.

9. See Fedotov, "Speech to UNWTO." See Allgood, "Criminal Nature."

10. Challender and MacMillan, "Poaching Enforcement Problem," 484-94. See also Haenlein and Smith, Poaching, 17.

11. Hagan, "'Organized Crime,' 127-37.

12. Ibid.

13. Rademeyer, Killing for Profit, 3-12.

14. Challender and MacMillan, "Poaching Enforcement Problem," 484.

15. See also Storti and de Grauwe, Illicit Trade Global Economy, 3-5.

16. Interview, TS and LT with Kurt Steiner, then Law Enforcement for Selous Game Reserve, June 2017; Interview, TS and LT with N1, Counter-Poaching Operator in Republic of Congo, May 2016; Interview, TS and LT with R1, Section Ranger, Kruger National Park, May 2014.

17. Interview, TS and LT with P1, Anti-Poaching Tracking Trainer and Operator in Savé Valley Zimbabwe, May 2014; Interview, TS and LT with M1, Anti-Poaching operator for GRU, May 2014.

18. Interview, TS and LT with M1, Anti-Poaching operator for GRU, June 2015; Interview, TS and LT with lan Stevenson, CEO of Conservation Lower Zambezi, May 2014.

19. Interview, TS and LT with E1, Anti-Poaching Analyst for Pathfinder Corporation, May 2014; Interview, TS and LT with BC, Head of Rhino Anti-Poaching Unit in Savé Valley Conservancy Zimbabwe, May 2014.

20. Interview, TS and LT with R1, Section Ranger, Kruger National Park, May 2014; Interview, TS and LT with P1, Anti-Poaching Tracking Trainer and Operator in Savé Valley Zimbabwe, May 2015.

21. This is a real threat with an outsized morale effect on poachers. See World Daily News, Harare, "Zimbabwe: Pride of Lions Kills 5 Poachers and Injures 3 Others," 28 June 2016. Accessed at http://worldnewsdailyreport.com/zimbabwe-prideof-lions-kills-5-poachers-and-injures-3-others/.

22. Interview, TS and LT with C1, Area Warden Lower Zambezi National Park Zambia, May 2014; Interview, TS and LT with Kurt Steiner, Anti-Poaching Advisor, Selous Game Reserve and Head of Law Enforcement, African Parks, June 2014.

23. Interview, KG with S1, Official in Gabon Parks, Feb 2016.

24. Interview, KG with Kurt Steiner, Anti-Poaching Advisor, Selous Game Reserve and Head of Law Enforcement, African Parks, Dec 2016. See also Makini Brice, 'Four rangers killed trying to stop elephant poachers in Congo park', the Independent, 10 October 2015.

25. Interview, KG with S1, Official in Gabon Parks, Feb 2016.

26. Rydell and Everingham, "Controlling Cocaine," xiv. 
27. Felbab-Brown, "Counternarcotics Policies in Afghanistan," 10; and Rubin, Afghanistan from the Cold War, 391.

28. Aronowitz, Human Trafficking, Human Misery, 15.

29. Territo and Matteson, Trafficking of Human Organs, 65.

30. McGuinness and McHale, "Transnational Organ Tourism," 684. See also Budiani, "Organ Transplants in Egypt," 126, 127.

31. Francis and Francis, "Stateless Crimes, Organ Trafficking," 284.

32. Greene, "Illicit Arms Trafficking," 153-5.

33. Challender and MacMillan, "Poaching Enforcement Problem," 484, 485.

34. Ferreira et al., "Chemical Horn Infusions," 60.

35. Ibid., 55.

36. CITES Secretariat, "Report of the Secretariat," 2013.

37. CITES Authority (Vietnam) and Humane Society International, "Vietnam Horn Demand Reduction."

38. Eloff and Lemieux, "Rhino Poaching in Kruger," 18-19.

39. Interview, TS and LT with P1, Anti-Poaching Tracking Trainer and Operator in Savé Valley Zimbabwe, May 2014; Interview, TS and LT with Dr. Freddy Safieli Manongi, Conservator for Ngorongoro Conservation Area Authority, June 2014.

40. Edward I. Steinhart, Black Poachers, White Hunters: A Social History of Hunting in Colonial Kenya. Oxford: James Currey, 2006, 83.

41. Montesh, "Rhino Poaching Organised Crime," 8-9.

42. Terhune, "Wildlife Trafficking."

43. Reuter and Caulkins, "Purity, Price, and Production," 10-12.

44. O'Neill, Insurgency and Terrorism, 13.

45. Mills and Wilson, "Who Dares Loses?" 22-31. Cf. Preston, "Civil War,"67, who argues it was at best stalemate tactically.

46. Crayne and Haenlein, "Poaching, Wildlife Trafficking," 39.

47. Interview, TS and LT with P1, Anti-Poaching Tracking Trainer and Operator in Savé Valley Zimbabwe, May 2014; Interview, TS and LT with M1, Anti-Poaching operator for GRU, May 2014.

48. UK MoD, JDP 0-0.1, "UK Glossary of Joint and Multinational Terms and Definitions."

49. Eloff and Lemieux, "Rhino Poaching in Kruger," 31.

50. Hayes, "Ivory Trafficking International Crisis."

51. Interview, TS and LT with E1, Anti-Poaching Analyst for Pathfinder Corporation, May 2014; Interview, TS and LT with BC, Head of Rhino Anti-Poaching Unit in Savé Valley Conservancy Zimbabwe, May 2014.

52. Interview, KG with S1, 08 Feb 16.

53. Interview, TS and LT with Dr. Freddy Safieli Manongi, Conservator for Ngorongoro Conservation Area Authority, June 2014.

54. Interview, TS and LT with BC, Head of Rhino Anti-Poaching Unit in Savé Valley Conservancy Zimbabwe, May 2014.

55. Bittel, "Social Media Slaughter."

56. Interview, TS and LT with M2, Anti-Poaching analyst for GRU, June 2015.

57. Interview, TS and LT with Damien Mander, Head of International Anti-Poaching Foundation, May 2014.

58. Interview, TS and LT with BC, Head of Rhino Anti-Poaching Unit in Savé Valley Conservancy Zimbabwe, May 2014; Interview, TS and LT with Kurt Steiner AntiPoaching Advisor, Selous Game Reserve and Head of Law Enforcement, African Parks, June 2014; Interview, TS and LT with lan Stevenson, CEO of Conservation Lower Zambezi, May 2014.

59. Eloff and Lemieux, "Rhino Poaching in Kruger," 32-5. 
60. Interview, KG with Kurt Steiner, Anti-Poaching Advisor, Selous Game Reserve and Head of Law Enforcement, African Parks, Dec 2016.

61. Gonzalez et al., "Unmanned Aerial Vehicles (UAVs)," 97.

62. Dudu Zwane and Sihle Mlambo, "Costs are a hurdle in rhino drone project." In IOL News, 07 May 2013. Accessed at http://www.iol.co.za/dailynews/news/costs-area-hurdle-in-rhino-drone-project-1511488.

63. Interview, TS and LT with BC, Head of Rhino Anti-Poaching Unit in Savé Valley Conservancy Zimbabwe, May 2014.

64. Interview, TS and LT with P1, Anti-Poaching Tracking Trainer and Operator in Savé Valley Zimbabwe, May 2014.

65. UK MoD, "JDP2-00, Intelligence and Understanding," para. 6-2.

66. Interview, TS and LT with P1, Anti-Poaching Tracking Trainer and Operator in Savé Valley Zimbabwe, May 2014.

67. Saporiti, "Managing National Parks."

68. Interview, TS and LT with M2, Anti-Poaching analyst for GRU, June 2015.

69. Hearne, "Hunting for profit."

70. Interview, TS and LT with Dr. Freddy Safieli Manongi, Conservator for Ngorongoro Conservation Area Authority, June 2014.

71. Interview, LT with A1, Head of Law Enforcement Majete National Park, November 2016.

72. Challender and MacMillan, “Poaching Enforcement Problem,' 484-94.

\section{Acknowledgements}

The authors acknowledge the assistance of The Prince of Wales Charitable Foundation (PWCF) in sponsoring the initial research to this article, and to the assistance of the charity Tusk in facilitating onwards research.

\section{Disclosure Statement}

No potential conflict of interest was reported by the authors.

\section{Bibliography}

\section{Primary}

CITES Authority (Vietnam) and Humane Society International. "Viet Nam Rhino Horn Demand Reduction Campaign." October 2014. Accessed June 2016. http://www.hsi. org/assets/pdfs/vietnam-rhino-horn-demand-poll.pdf

CITES Secretariat. Sixteenth Meeting of the Conference of the Parties, 2013. https://cites. org/eng/cop/16/doc/index.php

Emslie, Richard $\mathrm{H}_{\text {," }}$ et al. "African and Asian Rhinoceroses; Status, Conservation and Trade. A Report from the IUCN Species Survival Commission (IUCN SSC) African and Asian Rhino Specialist Groups and TRAFFIC to the CITES Secretariat pursuant to Resolution Conf. 9.14 (Rev. CoP15)." 2015.

Fedotov, Yuri (UNODC Executive Director), Speech to UNWTO African Tourism Ministers Meeting on Anti-poaching, Berlin, March 6, 2014. Accessed June 14, 2016. https:// www.unodc.org/unodc/en/eds-corner/speeches.html

MoD, U. K. Joint Intelligence Doctrine (JDP) 2-00, Intelligence and Understanding. London: HMSO, 2010. 
Save the Rhino. "Poaching Statistics." 2016. https://www.savetherhino.org/rhino_info/ poaching_statistics.

UK MoD, JDP 0-0.1. UK Glossary of Joint and Multinational Terms and Definitions. London: HMSO, 2006.

\section{Secondary}

Allgood, Beth. "Criminal Nature - The Dangerous Links Between Poaching and Organized Crime." International Fund for Animal Welfare, 2013. http://www.ifaw.org/unitedstates/news/criminal-nature-\%E2\%80\%93-dangerous-links-between-poaching-andorganized-crime.

Aronowitz, Alexis A., Human Trafficking, and Human Misery. The Global Trade in Human Beings. London: Praeger-Greenwood, 2009.

Bittel, Jason. "Social Media Slaughter: Social Media and e-Commerce Sites are the New Battlegrounds for the Illegal Wildlife Trade." National Resource Defence Council, March 12, 2015. www.nrdc.org.

Budiani, Debra. "Facilitating Organ Transplants in Egypt: An Analysis of Doctors'Discourse." Body \& Society 13, No. 3 (2007): 125-149.

Challender, Daniel W. S., and Douglas C. MacMillan. "Poaching is More than an Enforcement Problem." Conservation Letters 7, no. 5 (2014): 484-494.

Crayne, Stéphane, and Cathy Haenlein. "Poaching, Wildlife Trafficking and Conflict." In Poaching, Wildlife Trafficking and Security in Africa: Myths and Realities, edited by Cathy Haenlein and M. L. R. Smith, 38-57. London: RUSI, 2016.

Knight, Mike. "African Rhino Specialist Group Report". 10th Meeting of the IUCN/SCC African Rhino Specialist Group. Pachyderm 52 (2012): 7-19.

Davis, Glyn, and David Brown. Bushmeat and Livlihoods: Wildlife Management and Poverty Reduction. London: Blackwell Publishing, 2007.

Eloff, Corné and A. M. Lemieux. "Rhino Poaching in Kruger National Park." In Situational Prevention of Poaching, edited by Andrew M. Lemieux, 18-43. London: Routledge, 2014.

Felbab-Brown, Vanda. No Easy Exit: Drugs and Counternarcotics Policies in Afghanistan. Washington, DC: Brookings Institute, 2015.

Ferreira, Sam, Markus Hofmeyr, Danie Pienaar, and Dave Cooper. “Chemical Horn Infusions - A Poaching Deterrent or an Unnecessary Deception?" Pachyderm 55 (2014): 54-61.

Francis, Leslie P., and John G. Francis. "Stateless Crimes, Legitimacy, and International Criminal Law: The Case of Organ Trafficking." Criminal Law and Philosophy, 4 (2010): 283-295.

Gonzalez, Luis F., Glen A. Montes, Eduard Puig, Sandra Johnson, Kerrie Mengersen, and Kevin J. Gaston. “Unmanned Aerial Vehicles (UAVs) and Artificial Intelligence Revolutionizing Wildlife Monitoring and Conservation." Sensors 16, no. 1 (2016): 97.

Greene, Owen. "Examining International Responses to Illicit Arms Trafficking." Crime, Law and Social Change 33, no. 1-2 (2000): 151-190.

Haas, Timothy C., and Sam M. Ferreira. "Conservation Risks: When Will Rhinos Be Extinct." IEEE Transactions on Cybernetics (2016). http://ieeexplore.ieee.org/stamp/stamp. jsp?arnumber $=7236914$.

Hagan, Frank E. "'Organized Crime' and 'Organized Crime': Indeterminate Problems of Definition." Trends in Organized Crime 9, no. 4 (2006): 127-137.

Hayes, David J. "Ivory Trafficking: An International Crisis." Report for the Peninsula Event on February 4, 2015. http://www.worldaffairs.org.

Hearne, J. “Hunting for Profit." ORMS Today 26, no. 2 (1999): 40-43.

McGuinness, Sheelagh, and Jean V. McHale. "Transnational Crimes Related to Health: How Should the Law Respond to the Illicit Organ Tourism?" Legal Studies 34, no. 4 (2014): 682-708. 
Mills, Greg, and Grahame Wilson. "Who Dares Loses? Assessing Rhodesia's Counterinsurgency Experience." RUSI Journal 152, no. 6 (2007): 22-31.

Montesh, M. Rhino Poaching: A New Form of Organised Crime. Pretoria: University of South Africa, 2012.

O'Neill, Bard E. Insurgency and Terrorism: Inside Modern Revolutionary Warfare. Washington, DC: Brassey's, 1990.

Preston, Matthew. "Stalemate and the Termination of Civil War: Rhodesia Reassessed." Journal of Peace Research 41, no. 1 (2004): 65-83.

Rademeyer, Julian. Killing for Profit: Exposing the Illegal Rhino Horn Trade. Cape Town: Random House, 2012.

Reuter, Peter, and Jonathan P. Caulkins. "Purity, Price, and Production: Are Drug Markets Different?" in Illicit Trade and the Global Economy. Edited by Cláudia Costa Storti and Paul de Grauwe. London: MIT Press, 2012.

Rubin, Barnett R. Afghanistan from the Cold War Through the War on Terror. Oxford: Oxford University Press, 2013.

Saporiti, Nico. "Managing National Parks: How Public-Private Partnerships Can Aid Conservation." Public Policy for the Private Sector (IFC World Bank Group), no. 306 (2006). www.ifc.org.

Steinhart, Edward I., Black Poachers, and White Hunters. A Social History of Hunting in Colonial Kenya. Oxford: James Currey, 2006.

Terhune, Lea. "Wildlife Trafficking Is a Serious Problem, Lucrative Business." US Embassy Thailand, June 16, 2008. http://iipdigital.usembassy.gov/st/english/ article/2008/06/20080616142333mlenuhret0.8286859.html.

Wittig, Tim. "Poaching, Wildlife Trafficking and Organised Crime." In Poaching, Wildlife Trafficking and Security in Africa: Myths and Realities, edited by Cathy Haenlein and M. L. R. Smith, 77-101. London: RUSI, 2016. 